Background Head injury is a common presenting complaint to emergency departments and can generate clinical concern regarding non accidental injury (NAI) in young children. Clinicians are wary of exposing young children to unnecessary radiation but must balance this risk with their duty to protect the child and recognise abuse.

Objective To review all radiological imaging for trauma related head injuries in under- 2 year olds with the aim of establishing the incidence of non-accidental injury and identify associated features that may aid clinical decision making.

Design A single-centre retrospective note review was conducted over a 3 year period $(01 / 01 / 12$ - 01/01/2015) of children $<2$ years of age who presented to a tertiary paediatric hospital (RHSC, Glasgow) and received cranial imaging. Cases were identified using the PACS reporting system.

Results 75 cases were identified as trauma related neuroimaging over the study period and were subject to a detailed case note review. Median age was 39 weeks. There was a male predominance of $65 \%$. All 75 patients underwent CT head as their primary mode of trauma imaging.

Abnormal findings were reported in $79 \%$ with the most common finding being unilateral parietal skull fracture. $44 \%$ of those with positive findings on CT underwent a skeletal survey and 36\% had ophthalmology review. 31\% had a social work strategy meeting prior to discharge.

$17 \%$ of patients with positive findings on CT head were deemed to have sustained their injury secondary to abuse. None of these injuries were witnessed. Median age was 16 weeks. $70 \%$ of inflicted injuries had a complex skull fracture compared to $18 \%$ for those deemed accidental. $20 \%$ of the NAI group were previously known to social work compared to $3 \%$ in the accidental group.

Conclusion CT is the modality of choice for suspected skull fracture in RHSC, Glasgow. Younger age, unwitnessed injury, existing social work support and complex skull fracture were all associated more commonly with abusive injuries in this 3 year review. Our data has contributed to a larger UK study aiming to determine national variation in practice and deriving a clinical decision making tool to exclude/diagnose NAI as the cause of skull fracture.

\section{G144 PEER REVIEW EVALUATION AND NATIONAL GUIDELINE COMPARISON}

A Roberts, A Mandal, L Peers. Safeguarding, Sheffield Children's Hospital, Sheffield, UK

10.1136/archdischild-2018-rcpch. 140

Aims Peer review in child protection is an important aspect of reflective practice. It aims to impartially evaluatethe work of others, improving the quality of care. ${ }^{1}$

The RCPCH recommends organising and documenting monthly peer review meetings, lead by a chairperson.

This audit was designed to compare the current peer review system with the RCPCH national guidelines therefore highlighting areas of potential improvement within the peer review system.

Methods Stage 1 - Peer review forms from August 2014 to July 2015 were evaluated and compared to national $\mathrm{RCPCH}$ guidelines to look for possible areas of improvement. Following the initial audit, several recommendations were made; the peer review form was redesigned and a single chairperson was suggested.
Stage 2 - Peer review forms were evaluated from January 2016 to December 2016 to compare the effectiveness of the new form and to look for any further improvements in peer review.

Results From August 2014 to July 2015, peer review forms were insufficiently completed. Following the redesign of the form the documentation of peer review meetings improved (table 1).

\begin{tabular}{|c|c|c|c|c|}
\hline Question & $\begin{array}{l}\text { Audit, } \\
2014 / \\
2015\end{array}$ & $\begin{array}{l}\text { Audit, } \\
2014 / \\
2015\end{array}$ & $\begin{array}{l}\text { Re- } \\
\text { audit, } \\
2016\end{array}$ & $\begin{array}{l}\text { Re- } \\
\text { audit,2016 }\end{array}$ \\
\hline & Yes & No & Yes & No \\
\hline $\begin{array}{l}\text { Do peer review meetings occur every } \\
\text { week? }\end{array}$ & $88 \%$ & $12 \%$ & $82 \%$ & $18 \%$ \\
\hline $\begin{array}{l}\text { Are minutes recorded at every } \\
\text { meeting and are attendees always } \\
\text { listed? }\end{array}$ & $100 \%$ & $0 \%$ & $100 \%$ & $0 \%$ \\
\hline $\begin{array}{l}\text { Is a member of the CAU team } \\
\text { present to chair the meeting? }\end{array}$ & $93 \%$ & $7 \%$ & $100 \%$ & $0 \%$ \\
\hline Is the lead consultant present?* & $79 \%$ & $2 \%$ & $93 \%$ & $5 \%$ \\
\hline $\begin{array}{l}\text { During the meeting itself, is a } \\
\text { general consensus always reached? }\end{array}$ & $64 \%$ & $36 \%$ & $83 \%$ & $17 \%$ \\
\hline
\end{tabular}

* In 2014/2015, 19\% of meetings did not record the presence of a lead consultant. In $2016,2 \%$ of meetings did not record the presence of a lead consultant.

Conclusion The simple measure of changing the peer review form has improved the documentation of peer review meetings. Following Stage 2, there have been further improvements to the peer review form regarding patient documentation. This change will be evaluated in two years time.

\section{REFERENCE}

1. Libell N. Peer review in Safeguarding. https://www.rcpch.ac.uk/sites/default/files/ page/Peer\%20review\%20final.pdf (Accessed: 15 August 2017)

\section{G145 AN AUDIT OF ADEHERENCE TO SKELETAL SURVEY GUIDANCE IN SUSPECTED NON-ACCIDENTAL INJURY IN CHILDREN UNDER TWO YEARS OR AGE}

${ }^{1} \mathrm{KK}$ Tsang, ${ }^{2} \mathrm{~K}$ McKay, ${ }^{3} \mathrm{OG}$ Forbes. ${ }^{1}$ College of Medical, Vetinary and Life Sciences, University of Glasgow, Glasgow, UK; ${ }^{2}$ Child Protection Unit, Royal Hospital for Children, Glasgow, UK; ${ }^{3}$ Paediatrics, Royal Hospital for Children, Glasgow, UK

\subsection{6/archdischild-2018-rcpch.141}

Aim To audit compliance with local policy and RCPCH/RCR recommendation that all children under the age of two year who have a skeletal survey as part of a child protection investigation have follow up radiological imaging (either a full skeletal survey or chest $\mathrm{x}$-ray with oblique view of ribs) two weeks after initial imaging. In addition we aimed to assess the value of the skeletal survey in terms of identifying new injuries in children in our busy paediatric hospital.

Methods A five year (2012-2016 inclusive) retrospective analysis of radiology records and electronically archived in-patient notes was performed for all children under the age of two who underwent skeletal surveys as part of a child protection investigation. Reports of all skeletal surveys were analysed and cases where new injuries were identified were recorded. The standard was that all children had repeat imaging at 14 days 